\title{
Perbedaan Kemampuan Deteksi Kecurangan Laporan Keuangan antara Auditor Pria dan Wanita Berdasarkan Pengalaman Audit
}

\section{Lailah Fujianti}

Universitas Pancasila, Jakarta, Indonesia

\section{INFO ARTIKEL \\ JEL Classification : M42, D73}

\section{Keywords :}

fraud, experience, gender

\begin{abstract}
The purpose of this study is to investigate the impact of the experience of male auditors and female auditors on their ability to detect fraud, and to further explore the differences in the ability of male and female auditors who are experienced in detecting fraud.

The sample of this study was 78 auditors consisting of 47 men and 31 women. Purposive sampling is used to determine the number of research samples. The location of the auditor's office in the DKI Jakarta Region as a consideration in purposive sampling in determining the number of samples. Data analysis method used is Partial Least Square based on variance with multigroub test.

The results revealed the experience of male and female auditors had an impact on the ability to detect fraudulent financial statement presentation. Male and female auditors with similar experience are able to detect fraudulent financial statement presentation.

The practical implications of this study are expected to be useful as an input in improving the ability of auditors to detect fraud, as well as a basis for policy makers for authorities to consider the need for experience in improving the ability of auditors to detect fraud.

The originality of this study is that the ability of experience in improving fraud detection has been studied in many previous studies, but has not classified research samples by gender and has not distinguished the ability of male and female auditors who are experienced in fraud detection.
\end{abstract}

\section{ABSTRAK}

Tujuan penelitian ini adalah menginvestigasi dampak pengalaman auditor pria serta auditor wanita terhadap kemampuannya dalam deteksi kecurangan, serta mengkaji lebih jauh untuk mengetahui perbedaan kemampuan auditor pria dan wanita yang berpengalaman dalam mendeteksi kecurangan.

Sampel penelitian ini adalah 78 auditor yang terdiri dari 47 pria dan 31 wanita. purposive sampling digunakan untuk menentukan jumlah sampel penelitian. Lokasi kantor auditor di Wilayah DKI Jakarta sebagai pertimbangan dalam purposive sampling dalam penetuan jumlah sampel. Metode analisis data yang digunakan adalah Partial Least Square berbasis variance dengan uji multigroub. 
Hasil penelitian mengungkapkan pengalaman auditor pria serta auditor wanita berdampak terhadap kemampuan deteksi kecurangan penyajian laporan keuangan. Auditor pria maupun wanita yang memiliki pengalaman sama - sama mampu mendeteksi kecurangan penyajian laporan keuangan.

Implikasi praktis penelitian ini diharapkan bermanfaat sebagai input dalam meningkatkan kemampuan auditor dalam mendeteksi kecurangan, juga sebagai dasar bagi pengambil kebijakan bagi yang berwenang agar mempertimbangkan perlunya pengalaman dalam meningkatkan kemampuan auditor dalam mendeteksi kecurangan.

Adapun originalitas penelitian ini adalah kemampuan pengalaman dalam meningkatkan deteksi kecurangan banyak dikaji pada penelitian terdahulu, akan tetapi belum mengelompokkan sampel penelitian berdasarkan gender dan belum membedakan kemampuan auditor pria dan wanita yang berpengalaman dalam deteksi kecurangan.

\section{Pendahuluan}

Kecurangan

penyajian laporan keuangan merupakan penyajian yang salah dalam bentuk kuantitatif maupun kualitatif yang mengandung unsur kesengajaan. Kesengajaan ini mengandung maksud menipu para pemakai laporan keuangan. Perusahaan melakukan kecurangan penyajian laporan keuangan bila melaporkan asset atau pendapatan lebih tinggi dari yang seharusnya dan atau menyajikan kewajiban atau beban lebih rendah dari seharusnya.

Kecurangan penyajian laporan keuangan perlu diatasi agar tidak berdapak terhadap rendahnya kredibilitas pemakai laporan keuangan. Profesi auditor khususnya auditor ekternal merupakan profesi yang berperan dan bertanggung jawab dalam memberikan kredibilitas atas penyajian laporan keuangan serta mengurangi resiko informasi yang bersifat bias, menyesatkan, tidak akurat, tidak lengkap dan mengandung kesalahan material. Peran ini berdampak pada tuntutan kepada auditor supaya meningkatkan kemampuannya dalam mendeteksi kecurangan penyajian laporan keuangan.

Beberapa masalah kecurangan penyajian akhir-akhir ini menimbulkan issue tersendiri yang mempertanyakan kemampuan auditor dalam mendeteksi kecurangan penyajian laporan keuangan. Masalah-masalah tersebut itu muncul bersamaan dengan kasus-kasus yang menimpa penyajian laporan keuangan sejumlah perusahaan publik diantaranya kasus Enron tahun 2001, PT Kimia Farma tahun
2001 dan akhir-akhir ini tahun 2019, PT Garuda Indonesia. Perusahaan tersebut melakukan kecurangan yang sama yaitu overstated dalam penyajian laba perusahaan. Masalah-masalah ini kembali memunculkan pertanyaan akan kemampuan auditor mendeteksi keuangan.

Kecurangan penyajian laporan keuangan mengundang sejumlah reaksi dari berbagai pihak baik pemerintah, profesi auditor dan masyarakat lainnya serta tidak ketinggalan reaksi dari para peneliti. Banyaknya jumlah hasil penelitian dari berbagai negara yang terkait dengan kecurangan menandakan issue ini penting dan menjadi pusat perhatian banyak peneliti seperti Taiwan (Chen et al. 2019, Chen et al. 2017), China (Xu et al. 2018; Yang et al. 2018, Zhou et al. 2018, Liao et al. 2019), Jerman (Baader dan Krcmar, 2018), Inggris (Wang et al. 2019), Amerika Serikat (Cordis dan Lambert, 2017; Bai dan Koong, 2017), Korea (Kim et al. 2016), Malaysia (Nasir et al. 2019; Nasir et al, 2018 ). India (Gupta dan Gupta 2015), Uganda (Kabuye et al, 2017), Mesir (Kassem, 2018), Uni Emirat Arab (Halbouni et al. 2016; Awang dan Ismail, 2018) dan di Indonesia (Apriliana dan Agustina, 2017; Suryandar dan Anik, 2017).

Penelitian kecurangan selama ini di Indonesia banyak dikaitkan dengan variabel yang memberikan dampak keahlian auditor dalam deteksi kecurangan penyajian laporan keuangan. Variabel pengalaman auditor banyak dikaitkan dengan hal tersebut karena 
auditor berpengalaman akan berkemampuan untuk mengungkapkan kekeliruan (error) atau kecurangan (fraud) yang tidak umum dalam penyajian laporan keuangan serta mampu memaparkan penjelasan terhadap temuan tersebut (Mui, 2018; Hobson et al. 2017). Kondisi ini tidak sepenuhnya sejalan dengan hasil penelitian terbaru yang menunjukkan hasil in konsistensi. Salah satu hasil penelitian terbaru menunjukkan dukungan pengalaman terhadap kemampuan auditor dalam deteksi kecurangan penyajian laporan keuangan (Putra dan Dwirandra (2019); Said dan Munandar (2018), akan tetapi sebaliknya tidak berpengaruh menurut Rahim et al. (2019). In konsistensi hasil penelitian ini memotivasi peneliti mencermati penelitian tersebut. Kedua penelitian ini ternyata belum mengkelompokkan sampel auditor berdasarkan gender yaitu auditor pria dan wanita. Keberadaan wanita dalam top level manajemen belum mampu berperan dalam peningkatan kinerja perusahaan (Fujianti, 2018), akan tetapi wanita lebih takut menghadapi tuntutan hukum (Adhikari et al. (2015) sehingga lebih takut melakukan kecurangan. Pengelompokkan sampel auditor pria dan wanita dianggap penting karena wanita memiliki ketekunan dan ketelitian dibandingkan pria (Andarini dan Prasetya, 2017). Ketekunan dan ketelitian merupakan modal utama dalam mendeteksi termasuk dalam deteksi kecurangan penyajian laporan keuangan. Alasan tersebut memotivasi penelitian ini untuk mengkaji kemampuan auditor pria dan wanita dalam mendeteksi kecurangan ditinjau dari pengalaman mereka.

\section{Telaah Teori dan Pengembangan Hipotesis}

\section{Deteksi Kecurangan Laporan Keuangan}

Pendeteksian kecurangan merupakan upaya dalam mencegah terjadinya kecurangan. Pendeteksian ini juga berfungsi mempersempit peluang para pelaku kecurangan. Kecurangan memiliki makna tidak sama dengan dengan kekeliruan. Kekeliruan dapat diartikan sebagai kesalahan yang tidak disengaja sedangkan kecurangan kesalahan mengandung unsur kesengajaan. Kecurangan dibagi dua yaitu: salah saji yang timbul dari kecurangan dalam pelaporan keuangan dan kecurangan yang timbul dari perlakuan tidak semestinya terhadap aktiva dan hutang dan beban.

Secara umum faktor-faktor penyebab kecurangan berasal faktor internal dan faktor eksternal. Faktor internal meliputi:

a. Penyembunyian

Kesempatan ini muncul akibat ketidakmampuan pengendalian internal perusahaan dalan mendeteksi peluang terjadinya kecurangan. Ketidakdeteksian ini menyebabkan adanya kesempatan tersembunyi yang tidak diketahui pihak pengendali, sehingga menjadi celah atau kesempatan dalam melakukan kecurangan

b. Kesempatan

Adanya waktu dan tempat yang tepat bagi pelaku kecurangan sehingga memungkinkan melakukan kecurangan. Hal ini biasanya timbul dari kelemahan sistem dan internal control.

Adapun penyebab eksternal terjadinya kecurangan, antara lain:

a. Pengendalian internal perusahaan kurang atau tidak berfungsi dengan baik.

b. Ketidakharmonisan hubungan antara pekerja dengan pemberi kerja

c. Adanya motif balas dendam

Beberapa tindakan tindakan-tindakan yang dapat dilakukan mengurangi terjadinya kecurangan penyajian laporan keuangan, sebagai berikut :

a. Membangun mekanisme lingkungan organisasi untuk memastikan adanya kontribusi integritas penanggungjawab dalam proses penyusunan laporan keuangan.

b. Pengidentifikasian dan pemahaman mengenai unsur-unsur yang mengarah pada kecurangan.

c. Menciptakan mekanisme penilaian resiko kecurangan dalam perusahaan.

\section{Pengalaman Auditor}

Kamus Bahasa Indonesia menjelaskan pengalaman merupakan semua keadaan yang pernah dilalui, dijalani, dan dirasakan, serta ditanggung. Pengalaman auditor adalah. 
Rahayu, 2014: 7 menyatakan bahwa pengalaman seseorang diperlukan untuk memulai pekerjaan. Pekerjaan yang dijalankan oleh orang yang berpengalaman akan mendatangkan kinerja yang lebih baik daripada tidak berpengalaman. Begitu juga di dalam tugas audit pengelaman memegang peranan penting. Auditor junior memerlukan pengalaman dari penugasan audit dibawah pengawasan akuntan senior yang lebih berpengalaman. Hal ini dimaksudkan agar akuntan yang baru selesai pendidikan formalnya dapat segera menjalani pelatihan teknis dalam profesinya. Pemerintah mensyaratkan pengalaman kerja sekurangkurangnya tiga tahun sebagai akuntan dengan reputasi baik dibidang audit (SK Menteri Keuangan No. 43/KMK.017/1997 tanggal 27 januari 1997).

Menurut Matondang, 2010: 39, Auditor yang berpengalaman dapat dilihat dari banyak melakukan audit laporan keuangan baik dari segi lamanya waktu maupun banyaknya penugasan yang pernah ditangani. Bahwa semakin banyak pengalaman auditor semakin dapat menghasilkan berbagai macam dugaan dalam menjelaskan temuan audit. Suraida (dalam Matondang, 2010: 39-40) mengungkapkan bahwa akuntan pemeriksa yang berpengalaman akan membuat judgement yang relatif lebih baik dalam tugastugas profesional ketimbang akuntan pemeriksa yang belum berpengalaman. Akuntan pemeriksa yang berpengalaman mampu mengidentifikasi secara lebih baik mengenai kesalahan-kesalahan yang dilakukan secara sengaja (Kecurangan) maupun kesalahan-kesalahan yang dilakukan secara tidak sengaja dalam telaah analitiknya.

Audit menuntut keahlian dan profesionalisme yang tinggi. Keahlian tersebut tidak hanya diperoleh lewat pendidikan, Kecerdasan dan pelatihan (Chambers, 2014), tetapi juga pengalaman. Auditor yang berpengalaman akan memiliki lebih banyak pengetahuan dan struktur memori lebih baik dibandingkan auditor yang belum berpengalaman. Pengalaman auditor merupakan suatu hasil pemahaman tentang ilmu yang didapat dari proses pembelajaran melalui pendidikan formal maupun praktek langsung di lapangan. Pengalaman auditor yang berkenaan dengan kecurangan akan dapat berkembang dengan adanya programprogram pelatihan auditor atau dapat juga belajar dengan auditor senior yang memiliki banyak pengalaman-pengalaman. Pengalaman akan membedakan kemampuan Auditor mempersepsikan dan menanggapi informasi yang diperoleh selama pemeriksaan dan juga dalam memberikan kesimpulan audit terhadap objek yang diperiksa dalam bentuk pemberian opini (Sulistyowatidan Supriyati, 2015). Pengalaman memegang peranan dalam mengefektifkan internal control (Badara dan Saidin, 2013) sehigga dengan efektifitas ini mengurangi kecurangan. (Pramana et al 2016). Maka peneliti akan meneliti tentang variabel pengalaman auditor apakah memiliki pengaruh terhadap pendeteksian kecurangan laporan keuangan. Dengan demikian, hipotesis yang diajukan adalah sebagai berikut:

$\mathrm{H}_{1}$ : Pengalaman auditor pria berpengaruh positif terhadap pendeteksian kecurangan laporan keuangan .

$\mathrm{H}_{2}$ : Pengalaman auditor wanita berpengaruh positif terhadap pendeteksian kecurangan laporan keuangan.

\section{Gender}

Identifikasi laki-laki dan perempuan pria dan wanita dari segi biologis disebut gender (Hidayatunissa et al. 2018). Gender merupakan konsep budaya sebagai pembeda pria dan wanita dalam karakteristik emosional, prilaku, mentalitas. Penelitian terdahulu banyak mengkaji pengaruh jender dalam kaitannya dengan kinerja (Fujianti, 2018, Mohammad et al. 2018; Alazzani et al 2018)

Chung dan Monroe (2003) menyatakan wanita lebih efektif dan efisien dalam memproses informasi dalam tugas yang kompleks dibanding laki-laki karena keahlian yang dimiliki dalam membedakan dan mengselaraskan dalam hal ppengambilan keputusan. Pria relatif kurang mendalam menganalisis dalam pengambilan keputusan. Hal ini sesuai dengan penelitian yang dilakukan oleh Barbara (2003) yang menemukan bahwa wanita memiliki pertimbangan moral yang lebih tinggi dibandingkan dengan pria. CEO Wanita 
memilih kewajiban yang rendah daripada resiko (Faccio et al. (2016). Lenard et al, 2017 menenukan bahwa setidaknya kehadiran satu pimpinan wanita dalam perusahaan akan mengurangi prilaku melawan hukum untuk menyajikan penipuan dalam laporan keuangan. Berdasarkan hal ini maka hipotesa 3 sebagai beikut :

$\mathrm{H}_{3}$ : Ada perbedaan Pengalaman auditor wanita berpengaruh positif terhadap pendeteksian kecurangan laporan keuangan

\section{Kerangka Pemikiran}

Kerangaka Penelitian adalah sebagai berikut:

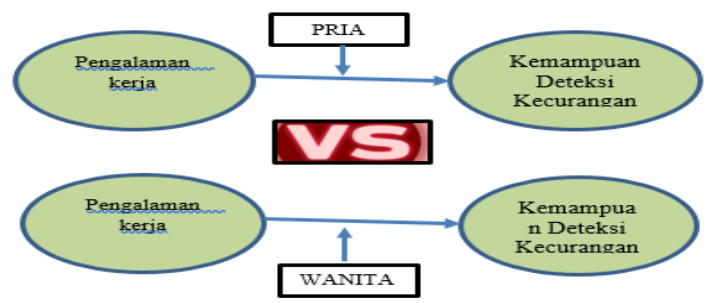

Gambar 2.1 Bagan Kerangka Pemikiran

\section{Metode Penelitian}

Jenis data penelitian berbentuk primer. Data ini dikumpulkan dengan instrumen berbentuk kuesioner. Data yang digunakan yaitu data primer. Sumber data diperoleh secara langsung dari kuesioner yang telah diisi oleh auditor DKI Jakarta. Sampel yaitu sebagian dari populasi atau dalam istilah matematik dapat disebut sebagai himpunan bagian atau subset dari populasi. Teknik pemilihan sampel menggunakan metode purposive sampling. Dalam sampling ini, terdapat dua tahap, yaitu tahap menentukan orang-orang yang ada pada daerah itu secara sampling juga, dengan menggunakan sampel ini peneliti melakukan penyederhanaan proses penarikan sampel agar mudah dalam pengumpulan data serta memperkecil kesalahan-kesalahan dalam pengolahan data. Penelitian dilakukan pada 10 (sepuluh) Kantor Akuntan Publik. Auditor yang bekerja di sepuluh KAP tersebut dijadikan responden sebagai objek penelitian.

Operasionalisasi variabel penelitian ini dijabarkan sebagai berikut :

Tabel 3.1

Operasionalisasi Variabel

\begin{tabular}{ll}
\hline Variabel & Sub Variabel \\
\hline Pengalaman & 1. Kemampuan \\
Auditor & kerja
\end{tabular}

2. Lamanya Kerja

1. Selalu melaksanakan tugas

2. Kemampuan memutuskan

3. Kemampuan mengenali kesalahan

4. Kemampuan mengenali masalah

5. Kemampuan memecahkan masalah

6. Kemampuan deteksi kecurangan

1. Dapat mengembangkan karir

2. Lama kerja sebagai auditor

Pendeteksian

Kecurangan

Laporan

Keuangan
1. Ciri Kecurangan

2. F

3. Mengetahu tanda-tanda terjadinya kecurangan

4. Standar audit guna deteksi kecurangan

5. Penemuan faktor - faktor terjadinya kecurangan

1. Perkiraan bentuk - bentuk kecurangan

2. Mengenali pihak - pihak pelaku kecurangan

3. Pemakaian prosedur dan metode yang efektif

4. Menyusun langkah-langkah untuk deteksi kecurangan
Model penelitian terdiri dari 3 (tiga) model pertama PLS auditor pria, PLS auditor wanita dan model multi grub. Ketiga persamaan tersebut sebagai berikut:

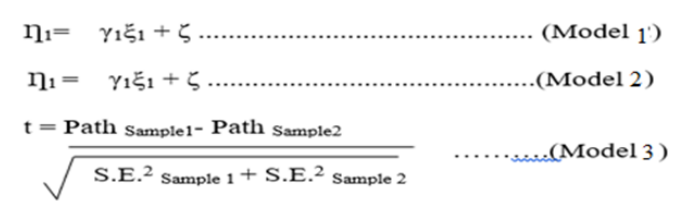

Salah satu pengujian instrument yaitu validitas. Pengujian ini dimaksudkan agar 
kuesioner memenuhi validitas. Kriteria kuesioner memenuhi validitas jika mampu mengungkapkan sesuatu yang seharusnya diukur (Ghozali, 2008). Uji validitas dalam penelitian ini menggunakan korelasi Pearson. Korelasi Pearson melihat nilai $r$ tabel dalam penentuan validitas. Kuesioner dinyatakan valid jika $r$ hitung lebih besar dari $r$ tabel.

Pengujian instrument selanjutnya adalah reliabilitas. Realiabilitas ini berfungsi memastikan bahwa kuesioner merupakan indikator variabel. Reliabilitas menunjukkan konsistensi jawaban selama beberapa waktu dari seorang responden. Variabel dinyatakan reliabel jika Cronbach's Alpha lebih besar 0,7 .

Analisis data dalam penelitian yaitu uji multigrub berbasis Partial Least Squares (PLS). Penggunaan analisis tersebut didasarkan pertimbangan jumlah sampel dan dasar teori yang lemah. PLS membutuhkan pengujian 2 (dua) pengujian yaitu pertama pengujian outer model dan berikutnya pengujian inner model.

Pengujian outer model adalah pengujian kesesuaian indikator dengan variabel kontruknya yang ada dalam model. Uji ini meliputi uji validitas model seta uji reliabilitas model. Nilai loading factor, communality, nilai AVE, nilai communality, cross loading dan nilai akar $A V E$ merupakan metode pengujian validitas model. Penelitian menggunakan nilai loading factor dalam penilaian validitas model. Suatu indicator dinyatakan memenuhi validtas jika nilai loading factornya diatas 0,7 .

Uji reliabilitas model dilakukan dalam rangka pembuktian keakurasian, konsistensi dan kecocokan indikator untuk mengukur kontruknya latennya. Reliabilitas model dapat juga dilihat dalam dua cara yaitu cronbach alpha dan composite reliability. Suatu indikator memenuhi syarat uji reliabilitas bila nilai cronbachs alpha dan nilai composite reliability diatas 0,70 .

Uji inner model merupakan uji kelayakan model struktural dalam PLS. Uji inner model dalam penelitian ini di bagi tiga yaitu uji kelayakan model struktural, uji hipotesa dan pengukuran besarnya pengaruh langsung, tidak langsung serta total pengaruh kepada variabel endogen. Penelitian ini menggunakan $R$ squared untuk menguji inner model penelitian. Menurut Latan dan Ghozali (2012), model kuat jika $R$ squared 0,67 , moderat jika nilai $R$ squared 0,33 dan lemah jika $R$ squared 0,67nilai 0,19 .

Hipotesa dalam penelitian ada 3 (tiga). Pengujian hipotesa diterima atau ditolak tergantung nilai $\mathrm{P}$ valuenya. $\mathrm{P}$ value bernilai lebih kecil dari 0,05 berarti hipotesa diterima dan sebaliknya hipotesa ditolak jika $\mathrm{P}$ value lebih besar dari 0,05.

\section{Hasil Penelitian dan Pembahasan}

Karakteristik objek penelitian berupa umur responden, jenis kelamin responden, pendidikan responden, jabatan responden, serta pengalaman responden. Responden dalam penelitian ini berjumlah 78 auditor berlokasi di DKI Jakarta.

Tabel 4.1

Karakteristik Responden

\begin{tabular}{llcl}
\hline & Dskripsi & Jumlah & $\%$ \\
\hline Jenis & Laki-laki & 47 & $60,3 \%$ \\
& Wanita & 31 & $39,7 \%$ \\
\hline Umur & $<30 \mathrm{Thn}$ & 56 & $71,8 \%$ \\
& 31-40 Thn & 14 & $17,9 \%$ \\
& $>40 \mathrm{Thn}$ & 8 & $10,3 \%$ \\
\hline $\begin{array}{l}\text { Pendidikan } \\
\text { Terakhir }\end{array}$ & D3 & 12 & $15,4 \%$ \\
& S1 & 65 & $83,3 \%$ \\
& S2 & 1 & $1,3 \%$ \\
& S3 & 0 & $0 \%$ \\
\hline Jabatan & Partner & 0 & $0 \%$ \\
& Manajer & 3 & $3,8 \%$ \\
& Supervisor & 1 & $1,3 \%$ \\
& Auditor & 25 & $32,1 \%$ \\
& Senior & & \\
& Auditor & 49 & $62,8 \%$ \\
\hline Junior & & \\
\hline Kengalaman & $<1$ Thn & 24 & $30,8 \%$ \\
& 1-5 Thn & 34 & $43,6 \%$ \\
& 5-10 Thn & 12 & $15,4 \%$ \\
& $>10$ Thn & 8 & $10,3 \%$ \\
\hline & pengalaman & kerja & auditor
\end{tabular}

Variabel pengalaman kerja auditor terdiri atas 8 butir pernyataan, dari ke- 8 
butir pernyataan adalah valid ( $\mathrm{r}_{\text {hitung }}>$ $\mathrm{r}_{\text {tabel }}$ ). Tabel di bawah ini menunjukkan hasil uji validitas dari variabel

pendeteksian kecurangan dengan 78 sampel responden.

Tabel 4.2

Hasil Uji Validitas Variabel Pengalaman Kerja Auditor

\begin{tabular}{cccc}
\hline Pernyataan & Nilai $\mathrm{r}_{\text {hitung }}$ & Nilai rtabel $_{\text { }}$ & Kriteria \\
\hline PA1 & 0,776 & 0,223 & Valid \\
PA2 & 0,749 & 0,223 & Valid \\
PA3 & 0,768 & 0,223 & Valid \\
PA4 & 0,840 & 0,223 & Valid \\
PA5 & 0,593 & 0,223 & Valid \\
PA6 & 0,666 & 0,223 & Valid \\
PA7 & 0,580 & 0,223 & Valid \\
PA8 & 0,626 & 0,223 & Valid \\
\hline
\end{tabular}

Uji validitas variable pendeteksian valid. Hasil uji validitas varibel tersebut dapat kecurangan ada delapan pertanyaan. dilihat pada table berikut : Kedelapan pertanyaan tersebut menunjukkan

Tabel 4.3

Hasil Uji Validitas Variabel Pendeteksian Kecurangan

\begin{tabular}{cccc}
\hline Pernyataan & Nilai $\mathrm{r}_{\text {hitung }}$ & Nilai $\mathrm{r}_{\text {tabel }}$ & Kriteria \\
\hline PDK1 & 0,751 & 0,223 & Valid \\
PDK2 & 0,640 & 0,223 & Valid \\
PDK3 & 0,499 & 0,223 & Valid \\
PDK4 & 0,714 & 0,223 & Valid \\
PDK5 & 0,763 & 0,223 & Valid \\
PDK6 & 0,610 & 0,223 & Valid \\
PDK7 & 0,505 & 0,223 & Valid \\
PDK8 & 0,450 & 0,223 & Valid \\
\hline
\end{tabular}

Pengujian reliabilitas dalam penelitian penelitian memenuhi syarat reliabilitas. Hasil ini untuk menunjukan semua variable hasil tersebut dapat dilihat pada table berikut :

Tabel 4.4

Hasil Uji Reliabilitas

\begin{tabular}{lccc}
\hline \multicolumn{1}{c}{ Variabel } & $\begin{array}{c}\text { Cronbach's } \\
\text { Alpha }\end{array}$ & $\begin{array}{c}\text { N of } \\
\text { Items }\end{array}$ & Keterangan \\
\hline Pengalaman Kerja Auditor & 0,848 & 8 & Reliabel \\
Pendeteksian Kecurangan & 0,784 & 10 & Reliabel \\
\hline
\end{tabular}

Pengujian outer model auditor pria menunjukkan semua indicator variable pengalaman auditor dan variable memiliki nilai loading factor diatas 0,7 . Hal ini berarti semua indikator kedua variabel tersebut memenuhi validitas model. 


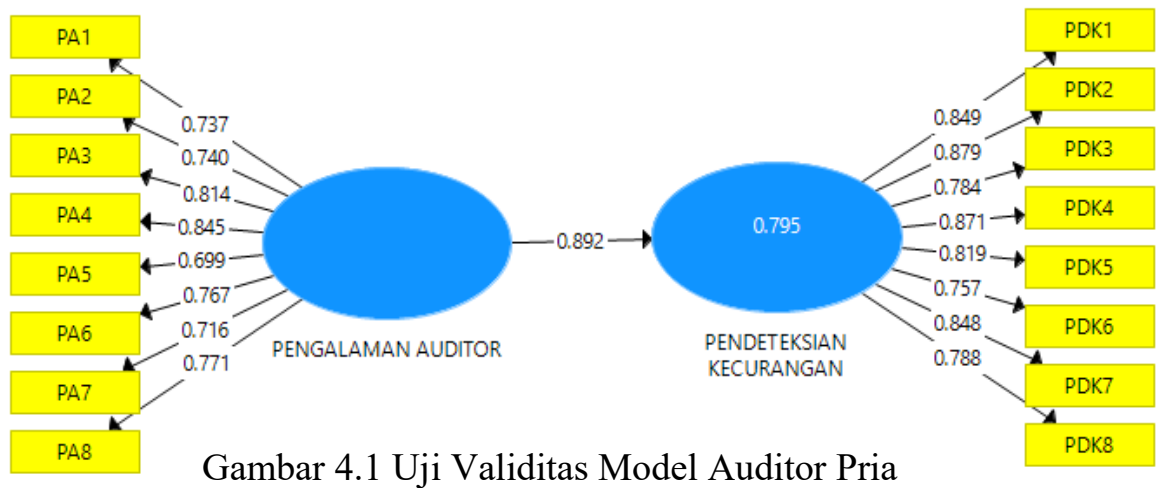

Hasil pengujian reliabilitas model Pria $\mathrm{Hal}$ ini mengindikasikan variable tersebut memenuhi reliabilitas model. Hasil pengujian reliabilitas variable pendeteksian kecurangan memiliki nilai Cronbach`a Alpha diatas 0,700. Hal ini mengindikasikan variable tersebut memenuhi reliabilitas model.

Tabel 4.5

Hasil Uji Reliabilitas Modal Wanita

\begin{tabular}{lcc}
\hline & $\begin{array}{c}\text { Cronbach`s } \\
\text { Alpha }\end{array}$ & $\begin{array}{c}\text { Composite } \\
\text { Reliabilitas }\end{array}$ \\
\hline Pengalaman & 0,897 & 0,917 \\
Pendeteksian & 0,933 & 0,945 \\
Kecurangan & & \\
\hline
\end{tabular}

Uji inner model dalam penelitian digunakan $\mathrm{R}$ squared. Hasil pengujian menunjukkan nilai $\mathrm{R}$ Squared 0,795 . Hal ini berarti model structural kuat. Nilai R Squared ini sekaligus menunjukkan bahwa pengalaman auditor pria mampu mempengaruhi kemampuan mendeteksi kecurangan sebesar 0,795 atau sebesar $79,5 \%$ dan sisanya variabel lain diluar penelitian ini.

Hasil Uji hipotesa 1 dapat dilihat pada tabel berikut. Hasil penelitian menunjukkan tingkat signifikan 0,00 lebih kecil dari 0,05 maka dapat disimpulkan hipotesa 1 diterima atau dengan kata lain pengalaman auditor pria berpengaruh terhadap kemampuan mendeteksi kecurangan dalam penyajian laporan keuangan.

Tabel 4.6

Hasil Uji Hipotesa 1

\begin{tabular}{llllcc}
\hline & $\begin{array}{l}\text { Original } \\
\text { Sample } \\
(\mathrm{O})\end{array}$ & $\begin{array}{l}\text { Sample } \\
\text { Mean } \\
(\mathrm{M})\end{array}$ & $\begin{array}{l}\text { Standard } \\
\text { Deviatian } \\
\text { (STDEV) }\end{array}$ & T Statistics & P Values \\
\hline $\begin{array}{l}\text { Pengalaman --> } \\
\begin{array}{l}\text { Pendeteksian } \\
\text { Kecurangan }\end{array}\end{array}$ & 0,892 & 0,897 & 0,035 & 22,57 & 0,00 \\
\hline
\end{tabular}

Pengujian outer model wanita atau model 2 menunjukkan indicator PA8 tidak memenuhi validitas model karena nilai loading faktornya di bawah 0,7 untuk itu indikator PA8 didrop dari model kemudian di dilakukan pengujian ulang. Hasil pengujian ulang dapat dilihat pada gambar berikut : 


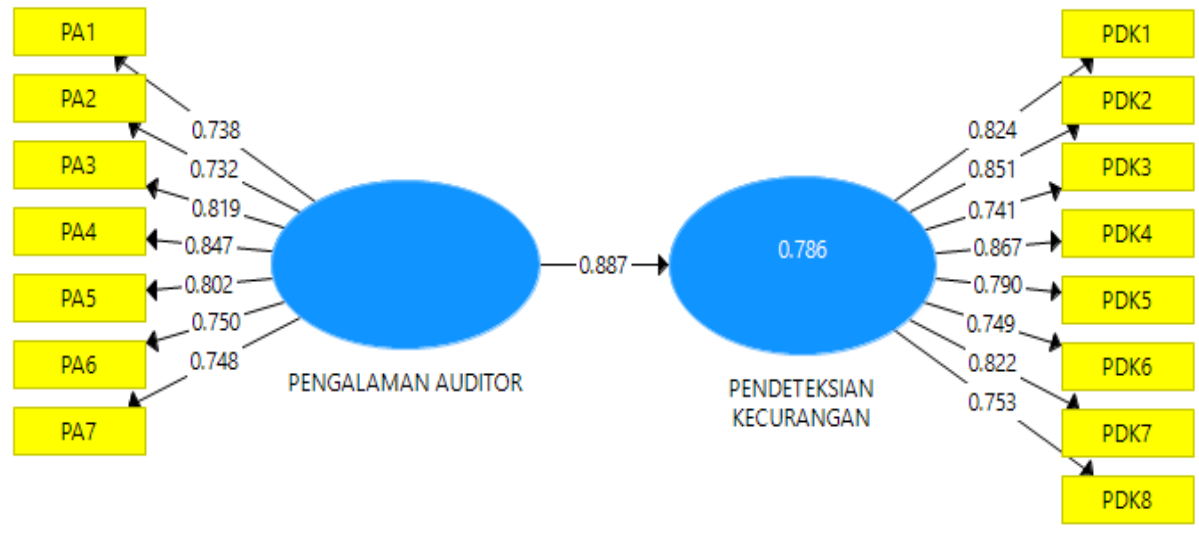

Gambar 4.2 : Uji Validitas Model Auditor Wanita

Hasil pengujian ulang menunjukkan semua indicator variable pengalaman audit menunjukkan nilai loading factor diatas 0,7 , sehingga semua indictor tersebut dinyatakan valid. Indikator Pendeteksian kecurangan juga menunjukkan nilai loading factor di atas 0,7 sehingga semua indicator memenuhi validitas model.

Uji inner model dalam penelitian digunakan $\mathrm{R}$ squared. Hasil pengujian menunjukkan nilai $\mathrm{R}$ Squared 0,786 . Hal ini berarti model structural kuat. Nilai R Squared ini sekaligus menunjukkan bahwa pengalaman auditor wanita mampu mempengaruhi kemampuan mendeteksi kecurangan sebesar 0,786 atau sebesar $78,6 \%$ dan sisanya variable lain diluar penelitian ini.

Hasil pengujian reliabilitas model wanita menunjukkan variable pengalaman memiliki nilai Cronbach'a Alpha diatas 0,7. Hal ini mengindikasikan variable tersebut memenuhi reliabilitas model.

Hasil pengujian reliabilitas variable pendeteksian kecurangan memiliki nilai Cronbach`a Alpha diatas 0,700. Hal ini mengindikasikan variable tersebut memenuhi reliabilitas model.

Tabel 4.5

Hasil Uji Reliabilitas Modal Wanita

\begin{tabular}{|c|c|c|}
\hline & $\begin{array}{l}\text { Cronbach`s } \\
\text { Alpha }\end{array}$ & $\begin{array}{l}\text { Composite } \\
\text { Reliabilitas }\end{array}$ \\
\hline Pengalaman & 0,891 & 0,914 \\
\hline $\begin{array}{l}\text { Pendeteksian } \\
\text { Kecurangan }\end{array}$ & 0,919 & 0,934 \\
\hline
\end{tabular}

Hasil Uji hipotesa 2 dapat dilihat pada tabel berikut. Hasil penelitian menunjukkan tingkat signifikan 0,00 lebih kecil dari 0,05 maka dapat disimpulkan hipotesa 2 diterima atau dengan kata lain pengalaman auditor wanita berpengaruh terhadap kemampuan mendeteksi kecurangan dalam penyajian laporan keuangan.

Tabel 4.6

Hasil Uji Hipotesa 2

\begin{tabular}{lccccc}
\hline & $\begin{array}{l}\text { Original } \\
\text { Sample (O) }\end{array}$ & $\begin{array}{l}\text { Sample } \\
\text { Mean (M) }\end{array}$ & $\begin{array}{l}\text { Standard } \\
\text { Deviatian } \\
\text { (STDEV) }\end{array}$ & T Statistics & P Values \\
\hline $\begin{array}{l}\text { Pengalaman ------ } \\
>\quad \text { Pendeteksian }\end{array}$ & 0,887 & 0,897 & 0,039 & 22,57 & 0,000 \\
Kecurangan & & & & & \\
\hline
\end{tabular}

Hasil perhitungan t hitung untuk model 3 sebagai berikut :

$$
\frac{0.892-0,887}{\sqrt{0,035^{2}+0,039^{2}}}=0,906
$$

Hasil Pengujian hipotesa3 menunjukkan nilai thitung 0,906 lebih lebih kecil dari 1,96. Hal ini berarti hipotesa 3 tertolak artinya auditor pria maupun auditor wanita jika 
berpengalaman sama sama memiliki kemampuan mendeteksi kecurangan.

Hasil pengujian hipotesa 1dan 2 menunjukkan pengalaman auditor pria dan wanita berpengaruh terhadap kemampuan mendeteksi kecurangan. Banyak pengalaman auditor maka kemampuan mendeteksi kecurangan juga semakin tajam (Rahim et al, 2019). Hal ini dikarenakan pengalaman kerja dapat memperdalam dan memperluas kemampuan kerja (Kuntari et al, 2017). Auditor yang berpengalaman mampu memahami penyebab kecurangan. Kecurangan ini diakibatkan kesalahan tampa unsur sengaja atau sebaliknya. Penelitian yang dilakukan oleh Kuria dan Muturi (2015) mendapatkan hasil bahwa pengalaman auditor berpengaruh positif pada pendeteksian kecurangan, hasil penelitian ini juga mendukung penelitian yang dilakukan oleh (Fitriyani, 2012; Matondang, 2010; Hammersley, 2011).

Hasil pengujian hipotesa 3 ditolak. Hal menunjukkan auditor pria maupun wanita yang memiliki pengalaman sama sama mampu mendeteksi kecurangan. Hasil penelitian ini sejalan dengan penelitian Hardies et al. (2009) menemukan bahwa tidak terdapat perbedaan kualitas audit antara auditor wanita dengan auditor pria.

\section{Kesimpulan}

Pengalaman berpengaruh terhadap kemampuan mendeteksi kecurangan. Auditor pria dan wanita yang berpengalaman samasama memiliki kemampuan mendeteksi kecurangan. Temuan penelitian ini belum bisa digeneralisasi karena jumlah reponden wanita hanya 31 dan pria 47 . Disamping itu penelitian ini hanya kepada auditor ekternal yang bekerja di kantor akuntan di Wilayah DKI Jakarta, sedangkan auditor pemerintah internal auditor belum dimasukkan dalam reeponden. Untuk sangat terbuka untuk penelitian-penelitian lanjutan yang terkait pendeteksian kecurangan.

\section{Daftar Pustaka}

Adhikari, B.K., Agrawal, A. and Malm, J. (2015). Do women stay out of trouble? Evidence from corporate litigation", working paper, Miami University, Oxford,
$\mathrm{OH}$ available at: http://ssrn. com/abstract $=2627846$.

Andarini, Y. D., \& Prasetya, T. A. E. (2017). The Correlation of Occupational Stress With Subjective Fatigue Women Workers In Weaving Loom Unit PT. X. Journal Of Vocational Health Studies, 1(1), 18-22.

Apriliana, S., Agustina, L. (2017). The Analysis of Fraudulent Financial Reporting Determinant through Fraud Pentagon Approach. Jurnal Dinamika Akuntansi, 9(2), 154-165.

Awang, Y., \& Ismail, S. (2018). Determinants of financial reporting fraud intention among accounting practitioners in the banking sector: Malaysian evidence. International Journal of Ethics and Systems, 34(1), 32-54.

Baader, G., \& Krcmar, H. (2018). Reducing false positives in fraud detection: Combining the red flag approach with process mining. International Journal of Accounting Information Systems, 31, 1-16.

Badara, M.S., Saidin, S.Z.. 2013. The Relationship between Audit Experience and Internal Audit Effectiveness in the Public Sector Organizations. International Journal of Academic Research in Accounting, Finance and Management Sciences. 3(3), 329-339.

Bai, S. and Koong, K. (2017). Financial and other frauds in the United States: a panel analysis approach. International Journal of Accounting \& Information Management, 25(4), 413-433.

Chambers, A.D. (2014), New guidance on internal audit - an analysis and appraisal of recent developments. Managerial Auditing Journal, 29(2): 196-218.

Chen, Y.J., Liou, W.C, Chen,Y.M., Wu., J.H. (2019). Fraud Detection for Financial Statements of Business Groups. International Journal of Accounting Information Systems, 32, 1-23.

Chen, Y.J., Wu., C.H., Chen, Y.M., Lia, H.Y., Chen, H.K. (2017). Enhancement of Fraud Detection for Narratives in Annual Report. International Journal of 
Accounting Information Systems, 26, 3245.

Cordis, A.S., M.Lambert, E.M . (2017). Whistleblower Laws and Corporate Fraud: Evidence from the United States. Accounting Forum, 41(4), 289-299.

Faccio, M., Marchica, M. and Mura, R. (2016), "CEO gender, corporate risktaking, and the efficiency of capital allocation", Journal of Corporate Finance, 39(1), 193-209.

Fujianti, L. (2018). Top Management Characteristics and Company Performance: An Empirical Analysis on Public Companies Listed in the Indonesian Stock Exchange. European Research Studies, 21(2), 62-76.

Gupta, P. K., \& Gupta, S. (2015). Corporate frauds in India-perceptions and emerging issues. Journal of Financial Crime, 22(1), 79-103.

Halbouni, S. S., Obeid, N., \& Garbou, A. (2016). Corporate governance and information technology in fraud prevention and detection: Evidence from the UAE. Managerial Auditing Journal, 31(6/7), 589-628.

Yendrawati, R., \& Mukti, D. K. (2015). Pengaruh gender, pengalaman auditor, kompleksitas tugas, tekanan ketaatan, kemampuan kerja dan pengetahuan auditor terhadap audit judgement. Asian Journal of Innovation and Entrepreneurship, 4(01), 18.

Hobson, J. L., Mayew, W. J., Peecher, M. E., \& Venkatachalam, M. (2017). Improving experienced auditors' detection of deception in CEO narratives. Journal of Accounting Research, 55(5), 1137-1166.

Kabuye, F., Nkundabanyanga, S. K., Opiso, J., \& Nakabuye, Z. (2017). Internal audit organisational status, competencies, activities and fraud management in the financial services sector. Managerial Auditing Journal, 32(9), 924-944.

Kassem, R. (2018). Exploring external auditors' perceptions of the motivations behind management fraud in Egypt-a mixed methods approach. Managerial Auditing Journal, 33(1), 16-34.

Kuntari, Y., Chariri, A., \& Nurdhiana, N. (2017). The Effect of Auditor Ethics, Auditor Experience, Audit Fees and Auditor Motivation on Audit Quality. Sriwijaya International Journal of Dynamic Economics and Business, 1(2), 203-218.

Kuria, P., \& Muturi, W. (2015). The relationship between the auditor's experience and fraud detection: A case of private firms within thika sub county, Kenya. European Journal of Business and Social Sciences, 4(4), 79-86.

Lenard, M. J., Yu, B., York, E. A., \& Wu, S. (2017). Female business leaders and the incidence of fraud litigation. Managerial Finance, 43(1), 59-75.

Liao, J., Smith, D., \& Liu, X. (2019). Female CFOs and accounting fraud: Evidence from China. Pacific-Basin Finance Journal, 53, 449-463.

Mui, G. Y. (2018). Defining Auditor Expertise in Fraud Detection. Journal of Forensic and Investigative Accounting, 10(2).

Mohammad, S. J., Abdullatif, M., \& Zakzouk, F. (2018). THE EFFECT OF GENDER DIVERSITY ON THE FINANCIAL PERFORMANCE OF JORDANIAN BANKS. Academy of Accounting \& Financial Studies Journal, 22(2).

Nasir, N. A. B. M., Ali, M. J., \& Ahmed, K. (2019). Corporate governance, board ethnicity and financial statement fraud: evidence from Malaysia. Accounting Research Journal, 32(3), 514-531.

Md Nasir, N. A. B., Ali, M. J., Razzaque, R. M., \& Ahmed, K. (2018). Real earnings management and financial statement fraud: evidence from Malaysia. International Journal of Accounting \& Information Management, 26(4), 508-526.

Pramana, A. C., \& Irianto, G. Nurkholis.(2016). The influence of professional skepticism, experience and auditors independence on the ability to detect fraud. Imperial Journal of 
Interdisciplinary Research,2(11), 14381447.

Rahim, S., Muslim, M., \& Amin, A. (2019). Red Flag And Auditor Experience Toward Criminal Detection Trough Profesional Skepticism. Jurnal Akuntansi, 23(1), 4661.

Said, L. L., \& Munandar, A. (2018). The Influence Of Auditor's Professional Skepticism And Competence On Fraud Detection: The Role Of Time Budget Pressure. Jurnal Akuntansi dan Keuangan Indonesia, 15(1), 104-120.

Sulistyowati, L., \& Supriyati, S. (2016). The effect of experience, competence, independence, and professionalism of auditors on fraud detection. The Indonesian Accounting Review (TIAR), 5(1), 95-110.

Suryandari, N. N. A., \& Yuesti, A. (2017). Professional scepticism and auditors ability to detect fraud based on workload and characteristics of auditors. Scientific Research Journal, 5(9), 109-115.

Wang, Y., Ashton, J. K., \& Jaafar, A. (2019). Does mutual fund investment influence accounting fraud?. Emerging Markets Review, 38, 142-158.

Xu, Y., Zhang, L., \& Chen, H. (2018). Board age and corporate financial fraud: An interactionist view. Long Range Planning, 51(6), 815-830.

Yang, D., Jiao, H., \& Buckland, R. (2017). The determinants of financial fraud in Chinese firms: Does corporate governance as an institutional innovation matter?. Technological Forecasting and Social Change, 125, 309-320..

Zhou, F., Zhang, Z., Yang, J., Su, Y., \& An, Y. (2018). Delisting pressure, executive compensation, and corporate fraud: Evidence from China. Pacific-Basin Finance Journal, 48, 17-34.. 